\title{
PERANCANGAN APLIKASI CHAT TRANSLATOR BERBASIS DESKTOP UNTUK KOMUNIKASI DUA BAHASA DALAM JARINGAN KOMPUTER
}

\author{
Pradana Nur Prasetya, Hero Wintolo, Nurcahyani Dewi Retnowati \\ Jurusan Teknik Informatika \\ Sekolah Tinggi Teknologi Adisutjipto \\ informatika@stta.ac.id
}

\begin{abstract}
One way of written communication is to send a message to the others. With the current technological developments, written communication can be supported by the computer and internet media so that messages sent can be delivered to target internet users in a short time and geographical distance is no longer a barrier of communication. In communicating between countries is often used in English, but that will be an obstacle when the language used to write the message was not understood by the other person and vice versa. Seeing this condition, then there needs to be an alternative media to overcome these obstacles. One of them is to design a bilingual (Indonesian-English) chat translator application. The system was created using Delphi 7 as a programming language and Oracle as Indonesian and English vocabulary storage database. Through this system, users can send messages using Indonesian or English and receive messages according to language used. The result from the design of this application indicates that the application is able to translate the text that is sent into the appropriate language which is controlled by interlocutors. So it can be a solution to communicate although with different language. However, the ability of the translator is very dependent on the current record in the dictionary table, so the translation can be developed in subsequent research to be more complete and better.
\end{abstract}

Keywords : chat translator application, bilingual communication, computer network

\section{Pendahuluan}

Perangkat lunak komputer yang digunakan untuk menerjemahkan bahasa yang berbeda sudah banyak dibuat dan digunakan oleh manusia. Perangkat lunak ini bekerja dengan cara menerjemahkan kata-kata yang berbeda menjadi bahasa yang dapat dipahami penggunanya sehingga menjadi kendala jika digunakanuntuk berkomunikasi dengan orang lain. Kendala ini adalah memindahkan hasil terjemahan ke perangkat lunak yang digunakan untuk berkomunikasi secara tulisan. Sehingga dilakukan tugas akhir dengan judul "Perancangan Aplikasi Chat Translator Berbasis Desktop Untuk Komunikasi Dua Bahasa Dalam Jaringan Komputer ${ }^{x y}$ ang menyatukan alat komunikasi tulisan dengan penterjemahannya untuk membantu manusia berkomunikasi dengan bahasa yang berbeda. 


\section{Metodologi}

\subsection{Tinjauan Pustaka}

Pada penelitian yang dilakukan oleh Roni Setiawan (2009), penelitian ini telah mengembangkan aplikasi chat yang berbeda dari apa yang tersedia sejauh ini, untuk layanan komunikasi antara pengguna yang berada di jaringan lokal. Aplikasi yang dibangun menggunakan Visual Basic 6.0 sebagai bahasa pemrograman. Fitur chat dapat digunakan oleh semua pengguna dan antar dua pengguna, juga fasilitas untuk mengirim file yang dapat dioperasikan dalam multi-user.

Pada penelitian yang dilakukan oleh Dewi Soyusiawaty (2009), penelitian ini membuat aplikasi kamus yang menerjemahkan bahasa Indonesia ke bahasa Sasak dan sebaliknya dengan teknologi WAP dengan menggunakan Macromedia Dreamweaver, WML, dan PHP.

Pada penelitian yang dilakukan oleh Hersatoto Listiyono (2009), penelitian ini menggunakan socket programming sehingga memungkinkan adanya komunikasi antara client dan server. Salah satu contoh sederhana penggunaan socket programming adalah pembuatan program untuk chating dengan Visual Basic Pada Sistem Operasi Windows.

\subsection{Analisis Sistem}

Dengan aplikasi chating berbasis desktop, setiap komputer yang terhubung dalam suatu jaringan dapat berkomunikasi antar komputer yang satu dengan komputer lainnya. Selain memiliki user interface yang interaktif, aplikasi chating berbasis client server ini memiliki kamus database yang berfungsi sebagai penerjemah bahasa yang dikirim antar $u$ ser melalui aplikasi chat translator.

Aplikasi chat translator ini menggunakan konsep jaringan peer to peer dengan topologi star, maka komputer pertama (user 1) yang menjalankan aplikasi chat translator tersebut akan bertindak sebagai server, dan komputer lainnya sebagai client. Jika server dimatikan/disconnect, maka secara otomatis user 2 akan bertindak sebagai server dan seterusnya. Fitur penerjemah bahasa hanya akan bekerja jika kedua user yang berkomunikasi menggunakan bahasa yang berbeda, dalam hal ini yaitu bahasa Indonesia dan bahasa Inggris. Jika kedua user menggunakan bahasa yang sama, maka pesan yang dikirim akan ditampilkan sesuai teks yang diketik. 
2.3 Perancangan Socket Stream Menggunakan Protocol TCP

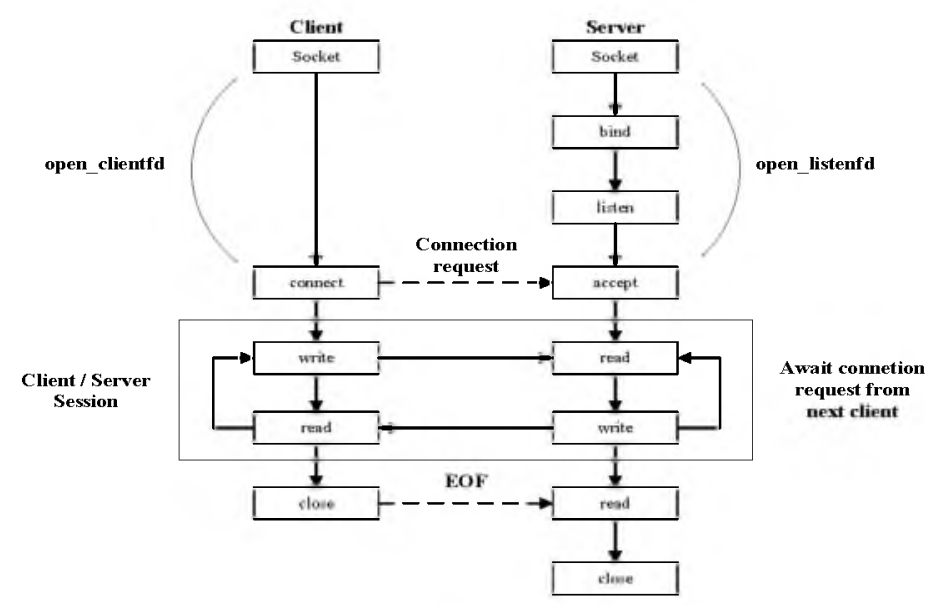

Gambar 1. Perancangan Socket Stream Menggunakan Protocol TCP

\subsection{Diagram Konteks}

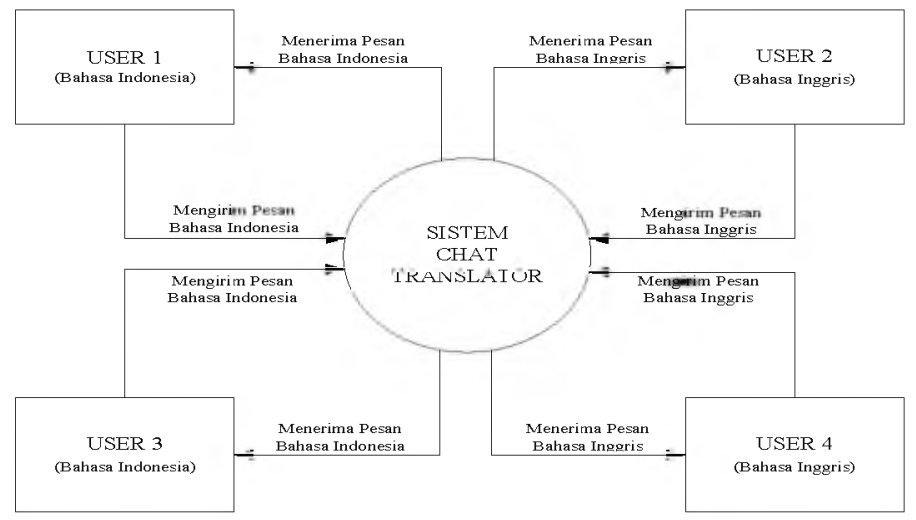

Gambar 2. Diagram Konteks Sistem Chat Translator Multiple User

\section{Hasil dan Pembahasan}

\subsection{Uji AplikasiDengan Jaringan LAN}

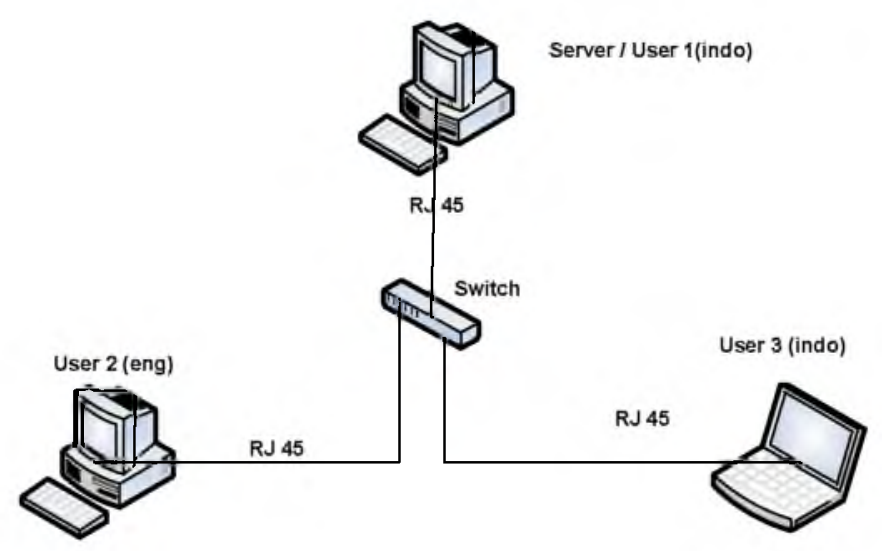

Gambar 3. Skema Uji Coba Chat Translator Dengan LAN 
Untuk mengecek bahwa 3 komputer telah tersambung dengan benar yaitu dengan melakukan "ping" pada setiap komputer ke alamat IP komputer lainnya. Proses ping dilakukan dengan membuka command prompt (CMD), setelah cmd terbuka ketikkan ping<spasi>IP komputer, misalnya "ping 192.168.1.1". Apabila mendapatkan balasan "reply" maka komputer telah tersambung dengan komputer yang lain, namun apabila mendapatkan balasan "time out" maka komputer belum bisa terkoneksi dengan komputer lainnya dan segera mencari permasalahan tersebut. Pengecekan jaringan dijelaskan seperti pada Gambar 4.

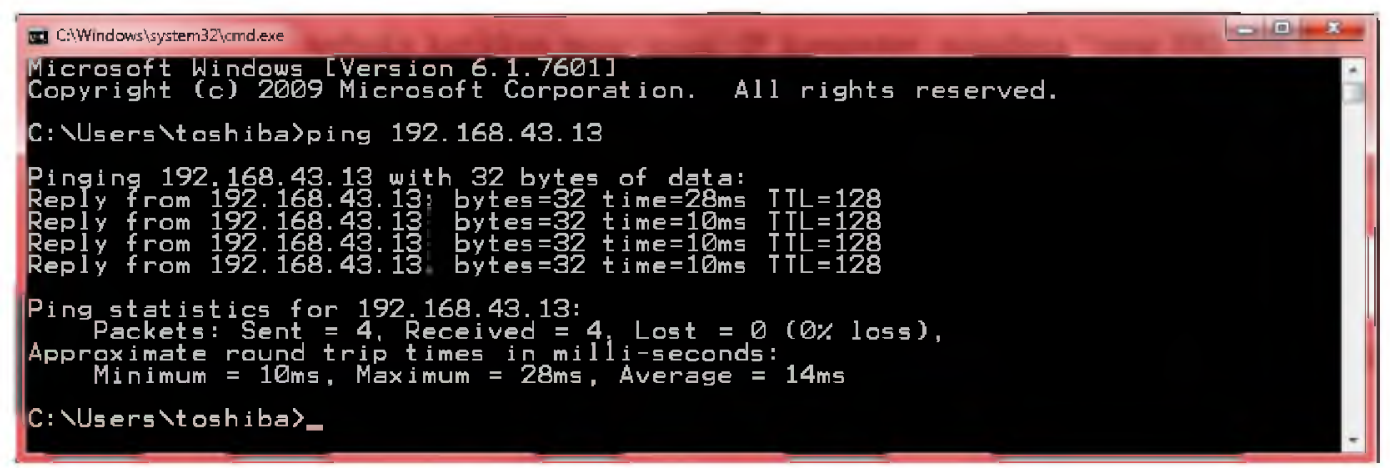

Gambar 4. Hasil"ping"ke Komputer Target

\subsection{Uji Aplikasi Menggunakan Jaringan Wifi}

Tahapan dalam melakukan uji fungsi selanjutnya adalah chat translator dengan wifiacces point. Uji chat translator dengan wifi merupakan uji coba aplikasi di dalam jaringan local yang memanfaatkan sebuah acces point dan dilakukan dilingkup wifi STTA. Pengujian ini dilakukan untuk menguji berkerja atau tidak aplikasi dalam berkomunikasi antar user dalam jaringan wifi dan untuk menguji kemampuan aplikasi dalam jaringan tersebut. Skema uji fungsi aplikasi chat translator di jaringan Wifi seperti pada Gambar 5.
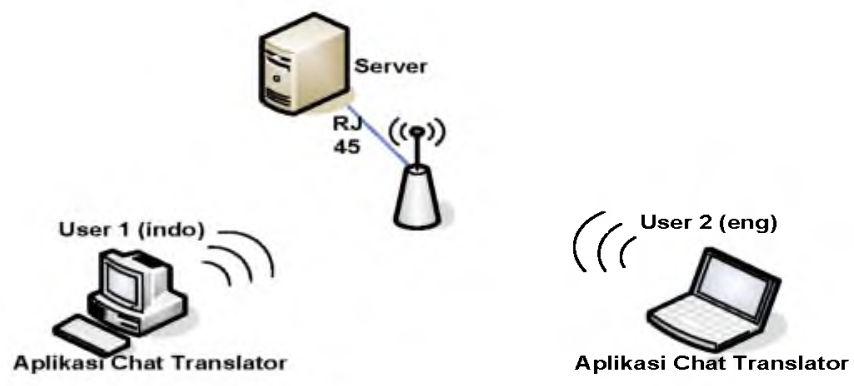

Gambar 5. SkemaUji Aplikasi dengan Wifi

Setelah uji coba ini dilakukan menggunakan dua komputer yang terhubung dengan wifi STTA, ujicoba ini dilakukan dengan cara melakukan percakapan antara user 1 dan user 2, dapat dilihat pada Tabel 1. 
Tabel 1. Percakapan AntaraUser 1 danUser 2 Dalam Jaringan Wifi

\begin{tabular}{|l|l|l|l|l|}
\hline \multirow{2}{*}{ No } & \multicolumn{2}{l|}{ User 1 (indonesia) } & \multicolumn{2}{l|}{ User 2(english) } \\
\cline { 2 - 5 } & Username & Message & Username & message \\
\hline 1 & prada & $\begin{array}{c}\text { apakah_kamu punya sebuah } \\
\text { mobil? }\end{array}$ & do_you have an car? \\
\hline 3 & prada & iya, aku memiliki avanza saya pinjam? & dana & yes, I have Avanza \\
\hline 4 & & $\begin{array}{c}\text { maaf, aku akan pergi ke } \\
\text { Yogyakarta }\end{array}$ & can I borrow ? \\
\hline 5 & prada & $\begin{array}{c}\text { tidak masalah, terimakasih } \\
\text { dana }\end{array}$ & $\begin{array}{c}\text { sorry, I will go to } \\
\text { Yogyakarta }\end{array}$ \\
\hline
\end{tabular}

\subsection{Uji Aplikasi Menggunakan Router (Beda Network)}

Tahapan dalam melakukan uji fungsi selanjutnya adalah uji coba chat translator dengan alamat IPnetwork yang berbeda menggunakan sebuah router. Pengujian ini dilakukan untuk kemampuan aplikasi dalam melakukan komunikasi antar user dalam jaringan lokal dengan subnet yang berbeda.Pengujian dilakukan di lab jaringan STTA dengan menggunakan dua perangkat komputer dan dua buah router CISCO. Pada kedua komputer tersebut diberikan alamat IP yang berbeda network, yaituuser 1 adalah 192.168.10.2 sedangkan user 2 adalah 11.11.11.2. Kegunaan router tersebut adalah agar 2 alamat network yang berbeda tersebut dapat saling terhubung.Skema uji fungsi aplikasi chat translatormenggunakan router (beda network) seperti pada Gambar 6.

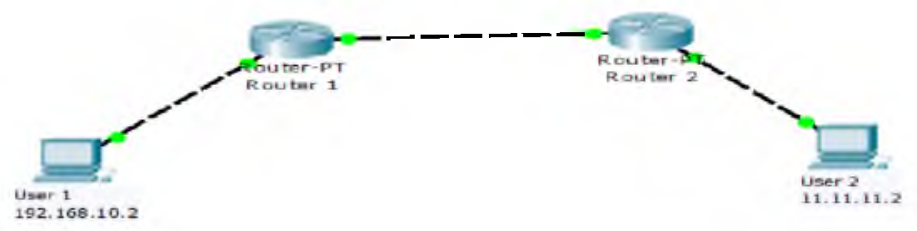

Gambar 6. Skema Uji Aplikasi dengan Router

Tabel 2. Alamat IP Pengujian Menggunakan Router Cisco

\begin{tabular}{|l|l|l|l|}
\hline Komputer & IP Address & Subnet Mask & Gateway \\
\hline User 1 & 192.168 .10 .2 & 255.255 .255 .0 & 192.168 .10 .1 \\
\hline User 2 & 11.11 .11 .2 & 255.255 .255 .0 & 11.11 .11 .1 \\
\hline
\end{tabular}


Berikut konfigurasi dari dua perangkat komputer dengan alamat IP berbeda network dan dua buah router CISCO tipe 2600 dijelaskan pada Tabel 2 dan Gambar 7.

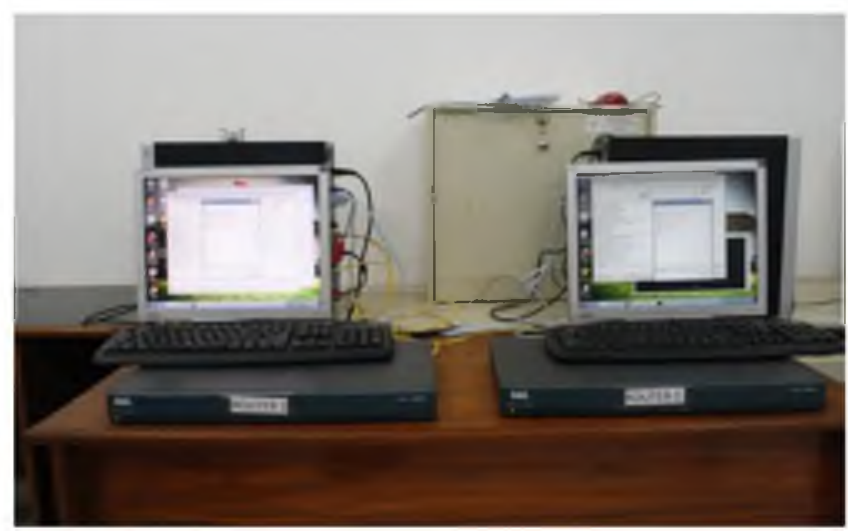

Gambar 7. Pengujian Aplikasi di Lab. Jaringan STTA

\subsection{Uji Aplikasi Dengan Jaringan Internet}

Tahapan dalam melakukan uji fungsi selanjutnya adalah dengan internet. Uji chat translator dengan internet merupakan uji coba aplikasi di dalam jaringan internet dengan menggunakan modem GSM. Pengujian ini dilakukan untuk menguji berkerja atau tidak aplikasi jika digunakan untuk berkomunikasi antar user dalam jaringan internet. Skema pengujian menggunakan media transmisi modem dapat dijelaskan pada Gambar 8.

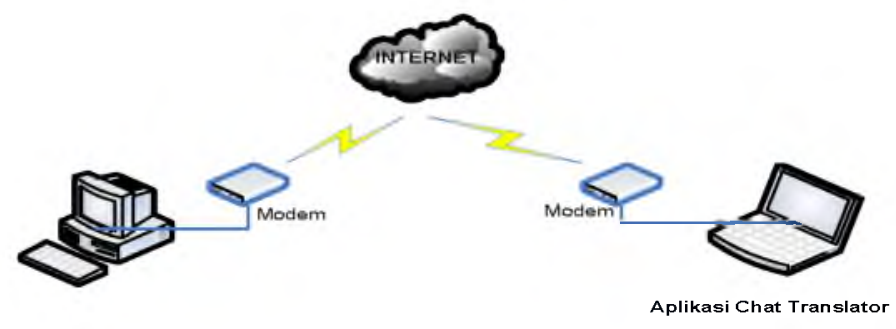

Gambar 8. Skema Pengujian Menggunakan Internet

Dalam pengujian ini menggunakan menggunakan 2 komputer dengan menggunakan media modem agar dapat terkoneksi dengan internet. Provider yang digunakan di dalam pengujian aplikasi menggunakan modem GSM dengan kartu "Three" dengan kecepatan rata-rata $128 \mathrm{kbps}$. IP address masing-masing komputer dapat dilihat pada Gambar 9.

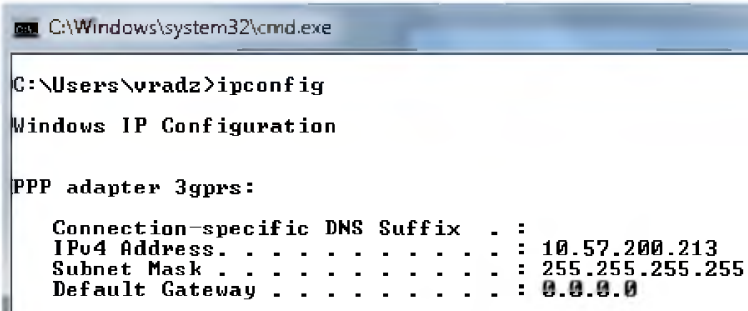




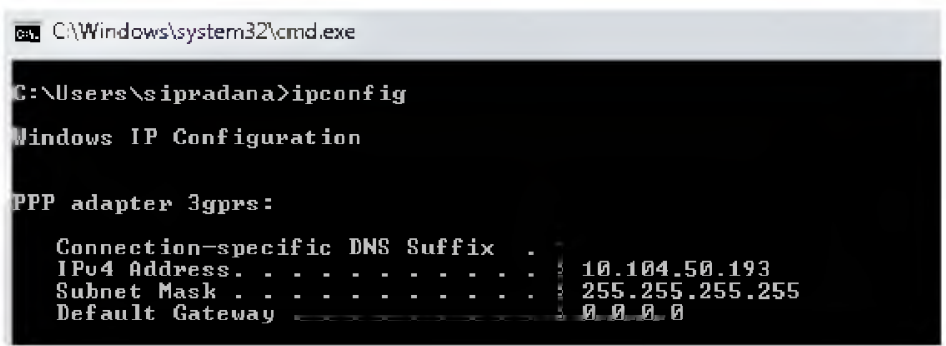

Gambar 9. Cek IP Address Menggunakan ipconfig Pada Dua Komputer.

Setelah mengetahui IP dinamis yang diberikan oleh penyedia layanan, kemudian melakukan konfigurasi untuk menghubungkan antar kedua komputer tersebut. Pada konfigurasi ini, IP address yang digunakan adalah 10.104.50.93 sebagai server dan IP address 10.57.200.213 sebagai client melalui port 1024. Setelah melakukan konfigurasi, kedua komputer tersebut telah dapat berkomunikasi dengan media transmisi internet. Selanjutnya melakukan login ke dalam aplikasi chat translator. Proses login ini ditampilkan pemberitahuan pada kolom log dalam form messenger untuk mengetahui aktifitas user. Kemudian dilakukan konfigurasi dan aktifitas $\log$ server

\subsection{Hasil Uji Aplikasi}

Dengan empat jenis pengujian yang dilakukan antara lain : uji aplikasi dengan jaringan LAN, jaringan Wifi, jaringan LAN (beda network), dan jaringan internet diharapkan dapat membuktikan availabilitas aplikasi yang mampu diterapkan di berbagai jenis jaringan komputer dengan kecepatan yang berbeda. Salah satu faktor yang mempengaruhi kecepatan yaitu koneksi internet yang digunakan pada saat pengujian. Tabel hasil pengujian ditunjukkan pada Tabel 3 dan Gambar 13.

Tabel 3. Hasil Pengujian Kecepatan Berdasarkan Tipe Jaringan

\begin{tabular}{|l|l|l|}
\hline Tipe Jaringan & $\begin{array}{l}\text { Kecepatan } \\
\text { Mengirim Pesan (s) }\end{array}$ & $\begin{array}{l}\text { Kecepatan } \\
\text { Menerima Pesan (s) }\end{array}$ \\
\hline LAN & 0.38 & 0.38 \\
\hline Wifi (dilakukan di STTA) & 1.76 & 1.76 \\
\hline Router (beda network) & 0.53 & 0.53 \\
\hline Internet (provider three) & 1.22 & 1.22 \\
\hline
\end{tabular}




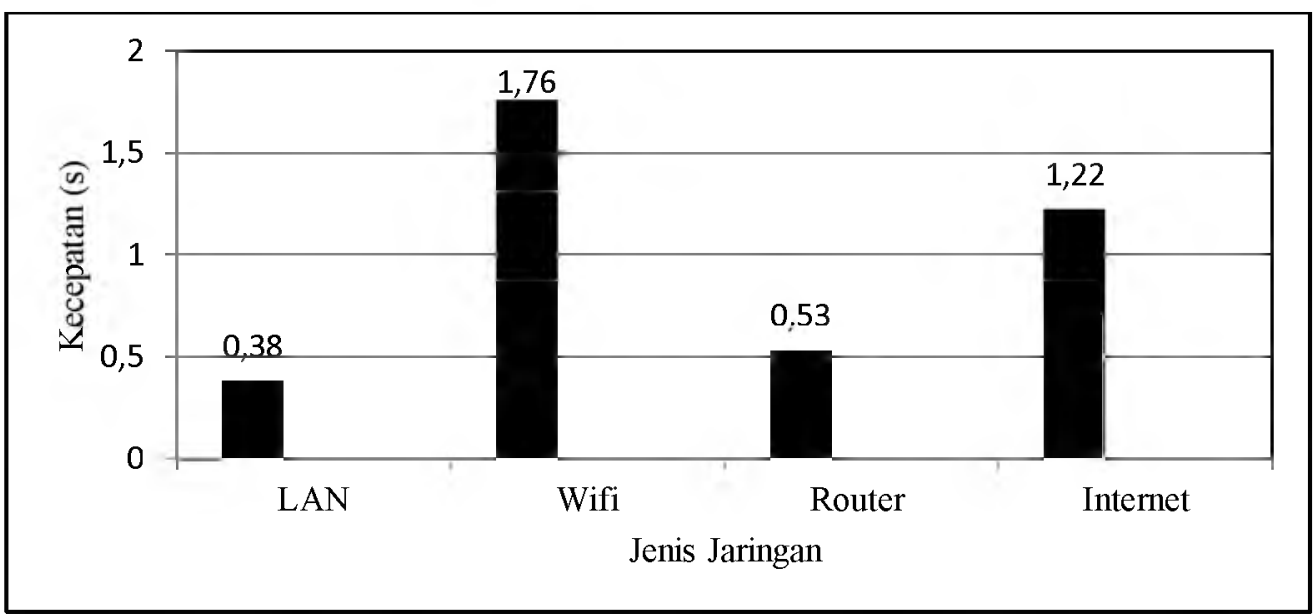

Gambar 13. Grafik Hasil Uji Kecepatan Aplikasi

\section{Kesimpulan dan Saran}

Kesimpulan yang diperoleh dari hasil analisa pengujian aplikasi chat translator adalah sebagai berikut :

1. Aplikasi yang dirancang setelah mengalami pengujian dapat berfungsi untuk komunikasi berbasis teks dari dua atau lebih pengguna komputer.

2. Aplikasi dapat diterapkan pada jaringan komputer yang memiliki alamat jaringan yang sama atau tidak sama dengan menerapkan routing statis/dinamis untuk menghubungkannya.

3. Kemampuan aplikasi dalam menerjemahkan kata sangat bergantung pada record yang ada dalam tabel kamus.

Dalam aplikasi ini juga memiliki saran yang dapat digunakan sebagai pengembangan aplikasi ini selanjutnya, antara lain :

1. Pengembangan terhadap sistem, sehingga tidak hanya bersifat aplikasi desktop saja tetapi juga dapat dibuat versi website dan versi mobile agar dapat digunakan sesuai kebutuhan pengguna.

2. Pengembangan terhadap kajian hasil penerjemah dengan tata bahasa yang lebih baik lagi supaya tidak menghilangkan makna dari pesan yang dikirimkan kepada lawan bicara.

\section{Daftar Pustaka}

Bahra, A1. 2005. Analisis dan Desain Sistem Informasi. Graha Ilmu. Yogyakarta.

Listiyono, Hersatoto. 2009. Program Socket Untuk Mengirim File Dengan Visual Basic Pada Sistem Operasi Windows. Jurnal Dinamika Informatika ISSN: 2085-3343 Volume I, No 1. Universitas Stikubank. Semarang.

Parameswaran, M., Susarla, A,. and Whinston, A.B. 2001. P2P Networking: an InformationSharing Alternative, Computer, vol 34, pp.31-38 July 2001.

Setiawan, Roni. 2009. Membangun Aplikasi Chatting Berbasis Multiuser. Jurnal Dasi ISSN:14113201 Volume 10, No 1. IST Akprind. Yogyakarta.

Soyusiawati, Dewi. 2009. Aplikasi Kamus Bahasa Indonesia - Bahasa Sasak Berbasis WAP. Seminar Nasional Informatika 2009 ISSN: 1979-2328. UPN “Veteran” Yogyakarta.

Wagito. 2005. Jaringan Komputer Teori dan Implementasi Berbasis Linux. Gavamedia. Jakarta. 